\title{
Extreme Conditions Modeling Workshop Report
}

\author{
R.G. Coe and V.S. Neary \\ Sandia National Laboratories \\ M.J. Lawson, Y. Yu and J. Weber \\ National Renewable Energy Laboratory
}

The Extreme Conditions Modeling Workshop was organized and run by the National Renewable Energy Laboratory and Sandia National Laboratories with funding from the Wind and Water Power Technologies Program within the U.S. Department of Energy's Office of Energy Efficiency and Renewable Energy.

The National Renewable Energy Laboratory is a national laboratory of the U.S. Department of Energy, Office of Energy Efficiency and Renewable Energy, operated by the Alliance for Sustainable Energy, LLC.

Sandia National Laboratories is a multi-program laboratory managed and operated by Sandia Corporation, a wholly owned subsidiary of Lockheed Martin Corporation, for the U.S. Department of Energy's National Nuclear Security Administration under contract DE-AC04-94AL85000.

Technical Report

NREL/ TP-5000-62305 - SNL/ SAND2014-16384R

July 2014

Contract No. DE-AC36-08GO28308 


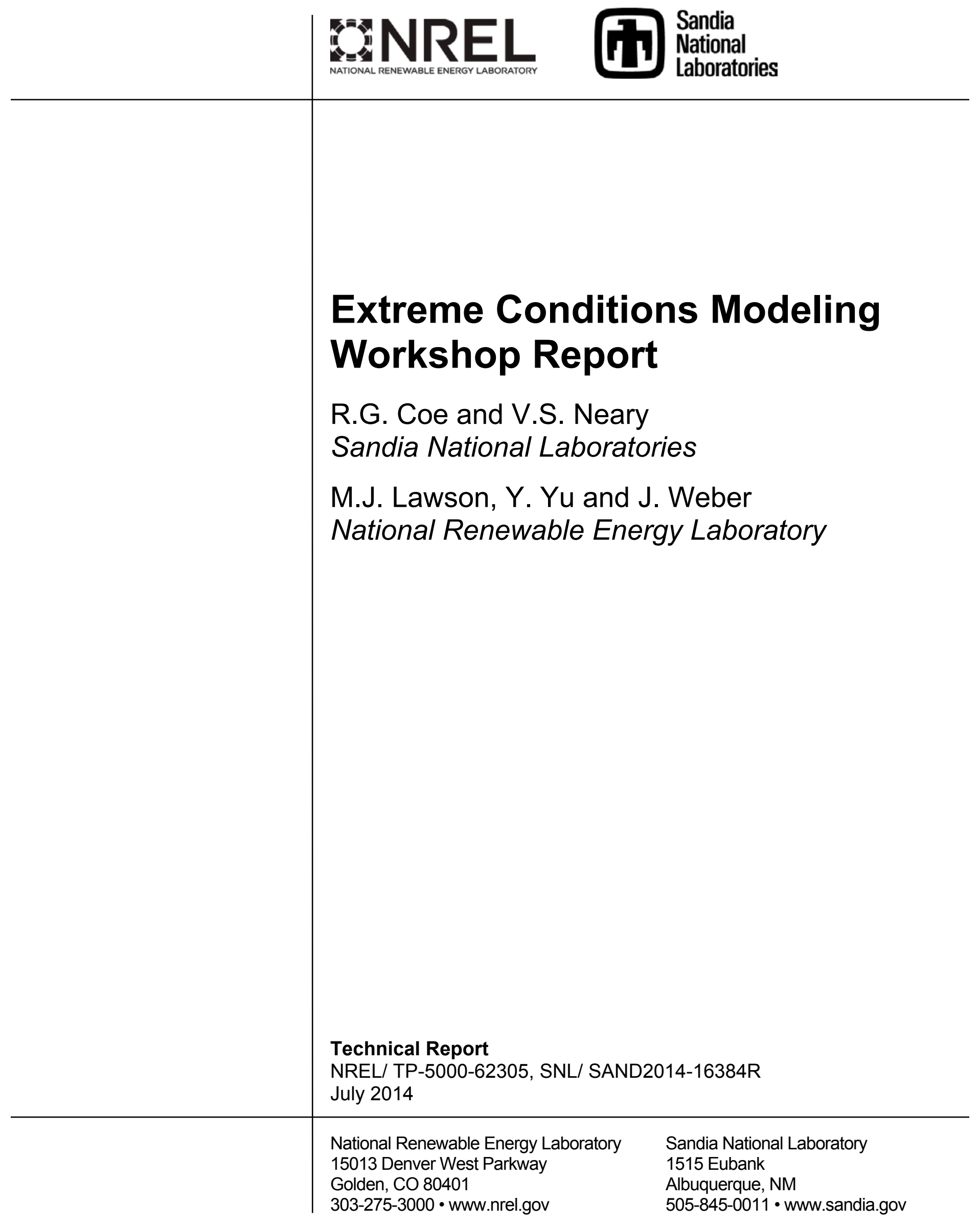




\section{NOTICE}

This report was prepared as an account of work sponsored by an agency of the United States government. Neither the United States government nor any agency thereof, nor any of their employees, makes any warranty, express or implied, or assumes any legal liability or responsibility for the accuracy, completeness, or usefulness of any information, apparatus, product, or process disclosed, or represents that its use would not infringe privately owned rights. Reference herein to any specific commercial product, process, or service by trade name, trademark, manufacturer, or otherwise does not necessarily constitute or imply its endorsement, recommendation, or favoring by the United States government or any agency thereof. The views and opinions of authors expressed herein do not necessarily state or reflect those of the United States government or any agency thereof.

Available electronically at http://www.osti.gov/bridge

Available for a processing fee to U.S. Department of Energy and its contractors, in paper, from:

U.S. Department of Energy

Office of Scientific and Technical Information

P.O. Box 62

Oak Ridge, TN 37831-0062

phone: 865.576.8401

fax: 865.576 .5728

email: mailto:reports@adonis.osti.gov

Available for sale to the public, in paper, from:

U.S. Department of Commerce National Technical Information Service 5285 Port Royal Road

Springfield, VA 22161

phone: 800.553 .6847

fax: 703.605.6900

email: orders@ntis.fedworld.gov

online ordering: http://www.ntis.gov/help/ordermethods.aspx

Printed on paper containing at least $50 \%$ wastepaper, including $10 \%$ post consumer waste. 


\section{Executive Summary}

Sandia National Laboratories (SNL) and the National Renewable Energy Laboratory (NREL) hosted the Wave Energy Converter (WEC) Extreme Conditions Modeling (ECM) Workshop in Albuquerque, New Mexico on May 13-14, 2014. The objective of the workshop was to review the current state of knowledge on how to numerically and experimentally model WECs in extreme conditions (e.g. large ocean storms) and to suggest how national laboratory resources could be used to improve ECM methods for the benefit of the wave energy industry. More than 30 U.S. and European WEC experts from industry, academia, and national research institutes attended the workshop, which consisted of presentations from WEC developers, invited keynote presentations from subject matter experts, breakout sessions, and a final plenary session.

The key findings and recommendations from the workshop were:

- The wave industry understands that ECM is a critical step in the device design process.

- Numerical and experimental ECM methods developed by the offshore oil \& gas and shipping industries, while useful, do not meet the needs of the WEC industry. Accordingly, research is needed to develop WEC-specific ECM methods.

- Open-source experimental data sets are needed to validate WEC device design and analysis methods. The national labs could assist the industry by developing these data sets.

- The WEC industry would benefit from a set of guidelines and best practices that describe how to numerically model WECs in extreme conditions.

- It is difficult to determine what meteorological and oceanographic conditions result in extreme loads on WEC devices. For example, it is not always the largest wave that causes the largest load, making it difficult to determine what wave conditions should be considered when performing survival analysis. The industry would benefit from research that helped develop methods of identifying when extreme events will occur.

- Certification bodies are starting to move towards risk-based certification of WEC devices and WEC developers should adopt a risk-based design approach. Many developers are already beginning to use this approach.

- Uncertainty in how to design WEC devices to survive extreme conditions is slowing the pace of technology development by increasing the investment risk. 


\section{Table of Contents}

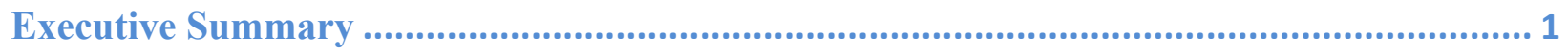

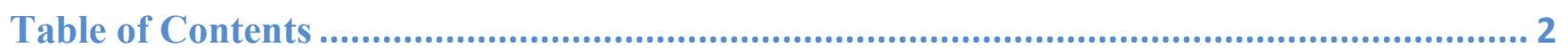

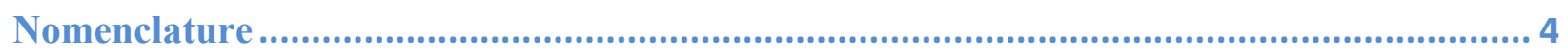

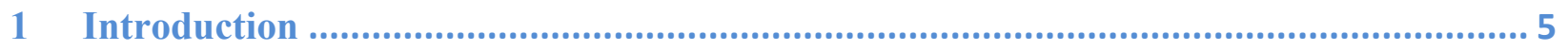

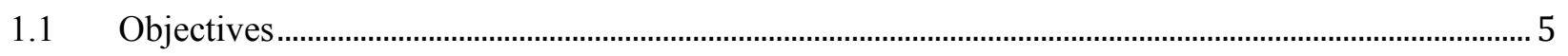

1.2 Definition of Extreme Conditions and Extreme Conditions Modeling ................................................ 5

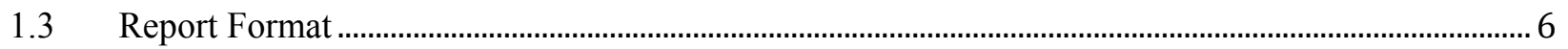

2 Workshop Description ............................................................................... 6

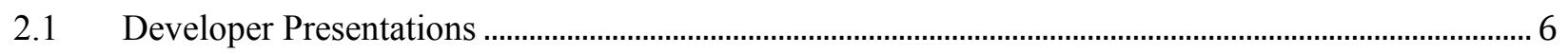

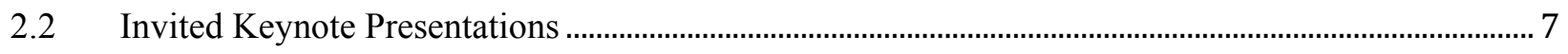

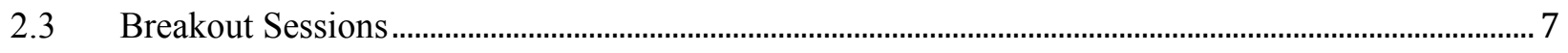

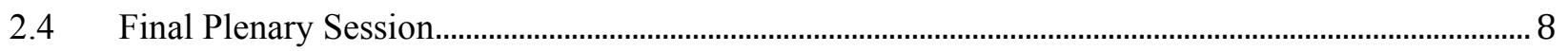

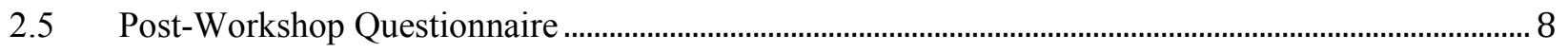

3 Workshop Findlings and Recommendations ..................................................... 8

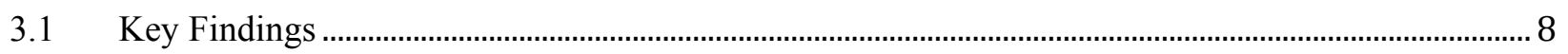

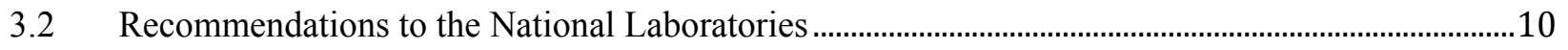

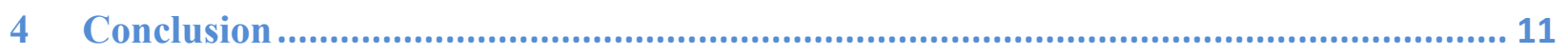

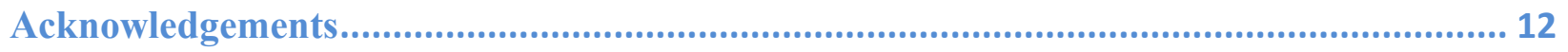

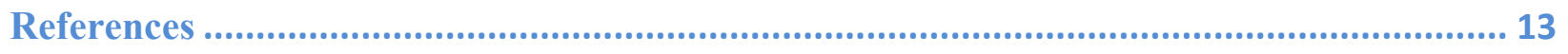

Appendix A Workshop Agenda …............................................................................... 14

Appendix B Workshop Attendees........................................................................................ 16

Appendix C Detailed Breakout Session Findings and Notes..................................... 17

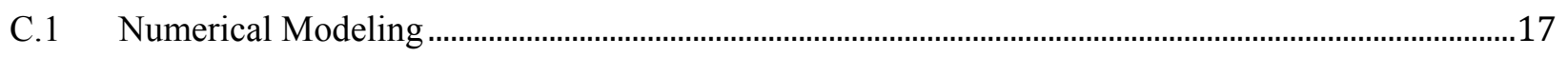

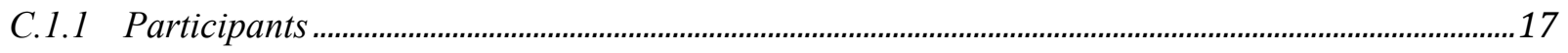

C.1.2 Key Findings and Recommendations.....................................................................................................17

C. 1.3 Notes ..............................................................................................................................................................18

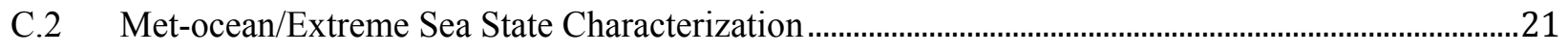

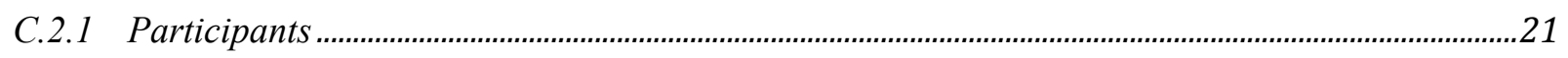

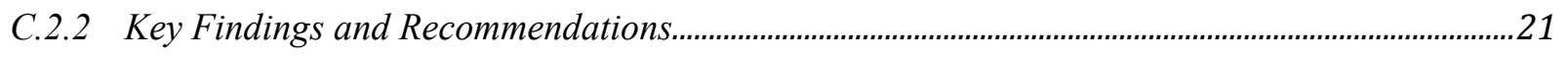

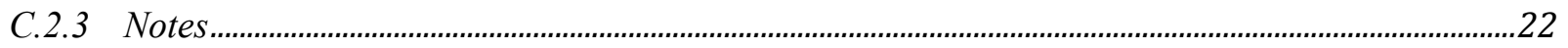

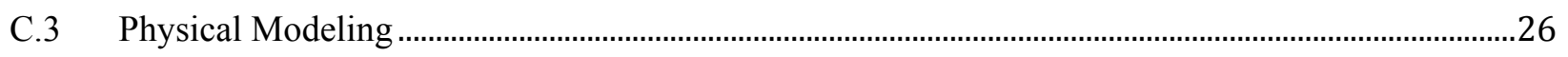

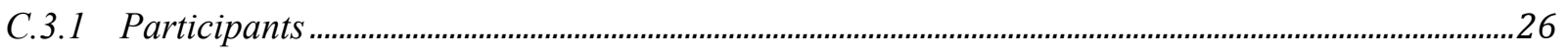

C.3.2 Key Findings and Recommendations....................................................................................................26

C.3.3 Notes .................................................................................................................................................................27

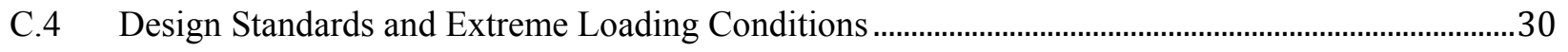




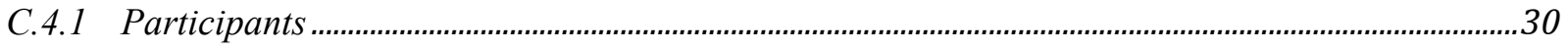

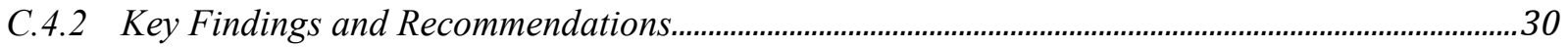

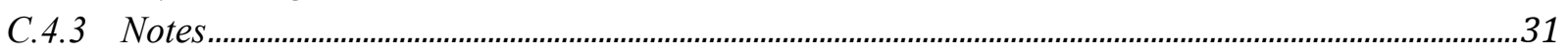

Appendix D Post-Workshop Questionnaire Responses ......................................... 35 


\section{Nomenclature}

CFD

DLC

DOE

DOFs

ECM

ESS

FMEA

IEC

ITTC

JIP

Met-ocean

NREL

OWC

O\&M

PCC

PTO

QOI

SNL

WEC
Computational fluid dynamics

Design load condition

U.S. Department of Energy

Degrees-of-freedom

Extreme conditions modeling

Extreme sea state

Failure mode and effects analysis

International Electrotechnical Commission

International Towing Tank Conference

Joint industry project

Meteorological and oceanographic

National Renewable Energy Laboratory

Oscillating water column

Operations \& maintenance

Power conversion chain

Power take-off

Quantity of interest

Sandia National Laboratories

Wave energy converter 


\section{Introduction}

Wave energy converters (WECs), which convert the kinetic energy in ocean waves into electricity, are designed to maximize fluid-structure interactions between the device and the ocean wave environment in order to optimize energy production. As a result, the hydrodynamic loads WECs experience during both normal operation and extreme conditions must be carefully considered during the device design process. Under most operational conditions, the relevant fluid-structure interactions can be modeled using common numerical and experimental methods [1]-[6]. Conversely, under extreme conditions, WEC devices experience large amplitude motions, wave overtopping, wave slamming, and other physical phenomena that are difficult to accurately simulate. These extreme conditions often determine the maximum design loads, and accordingly, the prediction of extreme loads is a critical step in the device design process.

The WEC industry has adopted extreme conditions design, modeling, and analysis techniques developed for offshore oil \& gas and naval architecture applications. While leveraging these existing design and modeling methodologies has greatly benefited the WEC industry in its nascent stages of development, extreme conditions modeling (ECM) methods must be further developed in order to advance technologies towards commercial viability [7].

To assess the ECM needs of the wave energy industry, Sandia National Laboratories (SNL) and the National Renewable Energy Laboratory (NREL) held an ECM workshop in Albuquerque, New Mexico on May 13-14, 2014. ECM involves several different disciplines, including numerical, experimental, and meteorological and oceanographic (met-ocean) modeling. It also takes into consideration design standards and identification of extreme loading conditions. As described in this report, the workshop was explicitly structured to address each of these topics.

\subsection{Objectives}

The overall goal of the ECM workshop was to identify research pathways through which national laboratory resources and expertise can be used to improve ECM methods for the benefit of the wave energy industry.

The specific objectives of the workshop were to:

- Review current practices and the state-of-the-art in experimental and numerical modeling methods for predicting device loads, motions, and performance in extreme conditions

- Identify challenges and gaps in the current modeling methods

- Identify research pathways that have the potential to advance ECM methods.

\subsection{Definition of Extreme Conditions and Extreme Conditions Modeling}

For the purposes of this document, extreme conditions are defined as met-ocean conditions that cause large loads (i.e. loads near or at the design limits) on a WEC device or any of its components. Accordingly, extreme conditions include large ocean storms where large device motions, wave slamming, and wave overtopping occur. Following this definition, extreme conditions may also include operational met-ocean conditions that cause device resonance. 
Extreme conditions modeling methods are, therefore, considered to be any numerical or experimental methods that can be used during the design process to predict loads during extreme sea states. Because extreme conditions often result in hydrodynamic loads due to nonlinear phenomena (e.g., wave slamming and overtopping), most extreme modeling methods must be able to accurately model these nonlinear phenomena.

\subsection{Report Format}

The remainder of this document describes the workshop proceedings, findings, and recommendations. Section 2 provides a description of the workshop. Section 3 then presents the key findings and recommendations from the workshop. The workshop's agenda, list of attendees, session notes, and the responses from the post-workshop questionnaire are presented in Appendices A - D, respectively. In addition, all workshop information, including presentation slides, can be accessed via the workshop website (http://en.openei.org/wiki/Wave Energy Converter Extreme Conditions Modeling Workshop). While some references are cited within this report, a more complete review of useful publications is presented in [8].

\section{Workshop Description}

The ECM workshop was attended by more than 30 wave energy experts from industry, academia, and national research institutes. A full list of participants and their affiliations is presented in Appendix B.

The workshop was divided into four sessions: (1) presentations from WEC developers, (2) invited keynote presentations, (3) breakout sessions, and (4) a final plenary session. The remainder of this section describes each session in detail. The full workshop agenda is presented in Appendix A. Other workshop documents can be downloaded from the workshop website (http://en.openei.org/wiki/Wave Energy Converter Extreme Conditions Modeling Workshop).

\subsection{Developer Presentations}

The workshop began with presentations from WEC technology developers Pelamis Wave Power, Resolute Marine Energy, Columbia Power Technologies, and WaveBob (see Table 1). These presentations focused on the specific ECM experience and design methods used by each developer. The developer presentations were followed by a presentation by Ryan Coe from SNL summarizing the NREL and SNL perspective on WEC survival analysis.

Table 1. Developer Presentation Details.

\begin{tabular}{|cc|}
\hline Developer & Speaker \\
\hline Pelamis Wave Power & Chris Retzler \\
\hline Resolute Marine Energy & Darragh Clabby \\
\hline Columbia Power Technologies & Pukha Lenee-Bluhm \\
\hline WaveBob & Jochem Weber \\
\hline
\end{tabular}




\subsection{Invited Keynote Presentations}

Following the developer presentations, invited keynote presentations on numerical modeling, experimental modeling, met-ocean analysis, and offshore oil \& gas experience were given by Armin Troesch (University of Michigan), Joop Helder (MARIN), Jim Thomson (University of Washington), and John Halkyard1 (Halkyard Associates), respectively. These presentations provided the attendees with background on the state-of-the-art WEC ECM methods and set the stage for the breakout sessions.

\subsection{Breakout Sessions}

After the developer and keynote presentations, the workshop participants formed four breakout groups based on their specific area of expertise.

Numerical modeling: This group focused on all aspects of numerical modeling relevant to ECM. Numerical modeling tools, ranging from high-fidelity models, such as Navier-Stokes computational dynamics, to reduced-order methods, such as potential flow simulations, were discussed.

Physical model testing: This group focused on all aspects of wave tank testing of WEC devices in extreme conditions. Bench-top and dry testing methods were also discussed.

Design standards and extreme loading conditions: This group covered design standards as they apply to the design and analysis of WEC devices in extreme conditions. This group also considered the problem of how to define the conditions that cause extreme loads, addressing the wellrecognized issue that the largest loads on a device may not be caused by the largest wave.

Met-ocean modeling: This group discussed current practices and new developments in estimating extreme sea states (ESS) through met-ocean measurements and modeling.

Each breakout group was tasked with answering the following questions with respect to their specific topic:

- What is the current practice and state-of-the-art?

- What are the gaps and obstacles; how should they be prioritized?

- What are the desired outcomes of a concerted research and development (R\&D) effort?

- What specific activities are needed to move forward and in what timeframe?

Each attendee selected a breakout session in which to participate. Attendees were encouraged to split their time between multiple breakout sessions if they felt they could contribute in more than one area. Each breakout session was led by an NREL or SNL staff member (see Table 22) who was responsible for taking notes during the session and for presenting the group's findings to the entire workshop in the final plenary session (see Section 2.4). Key findings, recommendations and notes from each breakout session are presented in Appendix C.

${ }^{1}$ Dominique Roddier gave John Halkyard's presentation as Mr. Halkyard was unable to attend the workshop. 
Table 2. Breakout Session Group Moderators.

\begin{tabular}{|cc|}
\hline Breakout Session & Group Moderator \\
\hline Numerical Modeling & Ryan Coe (SNL) \\
\hline Physical Model Testing & Michael Lawson (NREL) \\
\hline Design Standards & Jochem Weber (NREL) \\
\hline Met-ocean & Vince Neary (SNL) \\
\hline
\end{tabular}

\subsection{Final Plenary Session}

Following the breakout sessions, the entire workshop reconvened to review the findings of the breakout sessions and for a final group discussion. During the plenary session, each breakout session leader gave a summary of the discussion and conclusions from their respective breakout session. The key findings and recommendations for ECM research, based on the discussion during the final plenary session, are provided in Section 3.

\subsection{Post-Workshop Questionnaire}

At the conclusion of the workshop, the attendees were strongly encouraged to complete the online survey available at http://goo.gl/H0oRtv and shown in Appendix D, which also includes anonymized survey responses from the participants. Significant feedback from the survey is included in Section 3, Key Findings and Recommendations to National Laboratories.

\section{Workshop Findings and Recommendations}

The workshop presentations, notes from the breakout sessions and plenary session (Appendix C), and the responses to the post-workshop questions (Appendix D), were thoroughly reviewed by SNL and NREL to identify key findings and recommendations that can help the national labs direct resources in a manner that best addresses the ECM needs of the wave energy industry. This section presents these findings and recommendations in detail. Also note that key findings and recommendations from each breakout session are presented in Appendix C.

\subsection{Key Findings}

1. The wave industry understands the importance of ECM during the design process: The industry is aware that ECM must be performed to estimate design loads, but research is needed to identify what conditions result in extreme loads and how to accurately model WECs in extreme conditions using numerical and experimental methods.

2. Existing ECM methods do not meet industry needs: The WEC industry is currently using ECM methods adopted from oil \& gas, shipping, and naval architecture, but additional research is needed because the physics of wave energy devices are different from most traditional offshore devices (ships and oil \& gas platforms). Specifically:

a. A dichotomy exists in the design drivers for WECs and traditional offshore devices. WECs are generally designed to maximize fluid-structure interactions in order to maximize power performance, while traditional offshore devices are generally designed to minimize fluid-structure interactions for survivability. 
b. Ships and offshore platforms have a much larger scale than WECs, resulting in different Reynolds numbers and differences in the importance of viscous effects. In addition, the characteristic dimensions of WEC devices are typically smaller than a wavelength, whereas the characteristic dimension of ships and offshore platform are comparable to or larger than a typical wavelength.

c. WEC types and environments can vary greatly from moored surface deployments to seabed-mounted deployments, varying water depths, near shore and in shoaling conditions, thus requiring highly flexible modeling tools.

d. WECs tend to undergo large amplitude motions, and nonlinear hydrodynamic effects are therefore generally more important for WEC devices than other offshore structures.

3. Open-source experimental data sets are needed: Although there are several proprietary data sets from extreme conditions testing, there are no open-source (i.e. publically available) data sets.

4. There are no guidelines for numerical modeling of WECs in extreme conditions: Although there are a number of modeling methods capable of simulating the performance of WECs in extreme conditions (e.g. computational fluid dynamic [CFD] codes), there are no clear guidelines for how to perform ECM analyses. Most WEC companies are small, with limited in-house numerical modeling expertise and resources, and as such, the industry would benefit from guidelines on how to use existing numerical tools to model extreme events.

5. Extreme sea state characterization for WEC modeling is a challenge: Buoy observations are point measurements (they are therefore limited in spatial coverage) and may not represent extreme sea states at WEC deployment locations. Moreover, in order to get statistically significant data with which to estimate 25-, 50-, or 100-year storm conditions, long measurement histories (e.g. 20 years) are needed. Unfortunately these measurement histories do not typically exist at wave energy testing, demonstration, and potential commercial sites.

6. Predicting the conditions that cause extreme loads is difficult: It is not always the largest wave that causes extreme loads and more often it is a specific wave train. For example, one wave may position a WEC into a vulnerable position and a following wave, that would not normally damage the device, may impact the device in a way that causes an extreme loading event. In other words, the largest wave is not always the most harmful, and the operational design space must be searched to identify the sea states and wave trains that will most likely cause a failure of the WEC system. This contrasts with the extreme conditions analysis for the offshore oil \& gas industry, which are generally defined by the largest expected wave (often the 1,000- or 10,000-year wave).

7. The uncertainty of how to design for extreme conditions is slowing the pace of technology development by increasing the investment risk: A device failure during a field deployment can cause serious harm to the reputation of wave energy companies and decrease the chance of private and public investment, even if the experience gained from device or system failures during testing is valuable. Accordingly, developing improved ECM 
methods that decrease the uncertainty associated with ECM will significantly benefit the wave energy industry.

\subsection{Recommendations to the National Laboratories}

1. Create a U.S. "MARINET-like" program: The U.S. industry would benefit greatly from a testing program similar to the EU MARINET program (http://www.fp7-MARINET.eu/). This type of program would provide free access to wave tanks and expertise on how to perform experiments and numerical modeling in operational and extreme conditions. The vast majority of workshop attendees felt this type of program would be very valuable. The need for such a program may, to some extent, be met by the DOE WEC-Prize competition.

2. Generate open-source WEC data sets: There are few, if any, high-quality publically available data sets that can be used for numerical model validation. The industry would benefit greatly from open-source data for WECs in both extreme and operational conditions. The proposed US "MARINET-like" program from recommendation 1 could supply these datasets if the data is required to be made publically available.

3. Initiate a WEC code-comparison project: The WEC modeling community would benefit from a WEC code-comparison project that is similar to the Offshore Code Comparison Collaborative projects (OC3, OC4, and OC5) that have verified a wide spectrum of wind turbine models/assumptions against baseline tank tests. As demonstrated by OC3, OC4, and OC5, code comparison projects are very useful not only for`validating codes, but also for identifying areas where existing modeling methods need to be improved.

4. Develop efficient methods to search the design space for expected met-ocean conditions that are likely to cause extreme loading: Methods are needed to efficiently search the operational and survival design spaces for scenarios that pose a threat to WEC survival. One example of this type of method is the Design Loads Generator developed at the University of Michigan [10].

5. Build on existing offshore marine structures experience, guidelines, and standards for extreme sea state characterization: For ESS characterization, current practices for offshore marine structures [11]-[15] can be directly adapted. These include: (1) Use of hindcast simulations or buoy observations of sufficient duration (20 years preferred) and appropriate locations; (2) Extreme value theory and models used for extrapolation to events more extreme than those observed in a shorter period of record; (3) Contours in the environmental space (usually significant wave height and peak period) from which sea states that elicit extreme response can be derived; (4) Identification of one or more ESS (e.g., Hs100, T100) to describe single extreme wave or wave group (with assumed wave spectrum) as input for numerical or physical model simulation.

6. Numerical and experimental modeling guidelines and design standards are needed: Several numerical and experimental modeling methods are capable of predicting loads during extreme events. In addition, there are several design guidelines for WEC devices [10][14]. However, there are no well-documented procedures for how to use the existing modeling methods or standards to design WEC devices. The wave energy industry would benefit greatly from the development of an ECM recommended practices document as well as example analyses. In addition, existing offshore standards should be reviewed to 
determine what standards can be used by the WEC industry and in what areas new standards are needed. This need is being partially met by IEC-TC114.

7. Encourage the WEC industry to adopt risk-based design methodologies from shipping and offshore oil \& gas industries: The WEC industry and certification agencies are beginning to adopt risk-based design and device certification strategies pioneered by other offshore industries. The challenge of implementing a risk-based approach within the WEC industry lies in both the execution of the process and ensuring new frontiers related to WEC devices are considered and well understood. With a risk-based method, the likelihood and consequence of device and/or system component failures is evaluated with respect to the social, environmental, and economic impact of the failure. The risk-based design approach should employ estimates from the best available ECM methods and predictions of operational loads.

\section{Conclusion}

The ECM Workshop provided a forum for experts from industry, academia and research institutions to discuss the current state of ECM knowledge and to suggest future research paths to benefit the wave energy industry. Several shortcomings in existing WEC ECM methods were identified during the workshop and the workshop attendees identified and recommended research paths to help address the shortcomings. The recommendations developed during the ECM workshop span the sub-disciplines that comprise ECM (numerical and physical modeling, extreme sea state characterization and design standards). Successful execution of these recommendations will help advance wave energy technologies towards commercial viability. 


\section{Acknowledgements}

The National Renewable Energy Laboratory and Sandia National Laboratories would like to thank all the workshop attendees, who generously took two days out of their busy schedules to share their knowledge and expertise in the area of WEC extreme events modeling.

This study was supported by the Department of Energy (DOE), Office of Energy Efficiency and Renewable Energy (EERE), Wind and Water Power Technologies Office (WWPTO).

Sandia National Laboratories is a multi-program laboratory managed and operated by Sandia Corporation, a wholly owned subsidiary of Lockheed Martin Corporation, for the U.S. Department of Energy's National Nuclear Security Administration under contract DE-AC04-94AL85000.

The National Renewable Energy Laboratory is a national laboratory of the U.S. Department of Energy, Office of Energy Efficiency \& Renewable Energy, operated by the Alliance for Sustainable Energy, LLC. under contract No. DE-AC36-08G028308. 


\section{References}

[1] Kelley Ruehl, Carlos Michelen, Samuel Kanner, Michael Lawson, and Y. Yu, "Preliminary Verification and Validation of WEC-Sim, an Open-Source Wave Energy Converter Design Tool," in Proceedings of OMAE 2014, San Francisco, CA, 2014.

[2] J. Lucas, M. Livingstone, M. Vuorinen, and J. Cruz, "Development of a wave energy converter (WEC) design tool - application to the WaveRoller WEC including validation of numerical estimates," in ICOE 2012, Dublin, Ireland, 2012.

[3] A. Babarit, J. Hals, M. J. Muliawan, A. Kurniawan, T. Moan, and J. Krokstad, "Numerical Benchmarking Study of a Selection of Wave Energy Converters," Renew. Energy, vol. 41, pp. 44-63, May 2012.

[4] “Orcina: OrcaFlex." [Online]. Available: http://www.orcina.com/SoftwareProducts/OrcaFlex/. [Accessed: 10-May-2013].

[5] G. Payne, Guidance for the experimental tank testing of wave energy converters. SuperGen Marine, 2008.

[6] M. B. Topper, Guidance for Numerical Modelling in Wave and Tidal Energy. SuperGen Marine, 2010.

[7] NREL, "NREL MHK Workship Report," 2013.

[8] R. G. Coe and V. S. Neary, "Review of Methods for Modeling Wave Energy Converter Survival in Extreme Sea States," in Proceedings of the 2nd Marine Energy Technology Symposium, Seattle, WA, USA, 2014.

[9] "Interim Guidance on Hurricane Conditions in the Gulf of Mexico," American Petroleum Institute, API BULLETIN 2INT-MET, 2007.

[10] L. K. Alford, D.-H. Kim, and A. W. Troesch, "Estimation of extreme slamming pressures using the non-uniform Fourier phase distributions of a design loads generator," Ocean Eng., vol. 38, no. 5-6, pp. 748-762, Apr. 2011.

[11] DNV, Guidelines on design and operation of wave energy converters. Det Norske Veritas, The Carbon Trust, 2005.

[12] DNV, "Environmental Conditions and Environmental Loads," Det Norske Veritas, DNV-RPC205, 2007.

[13] DNV, "Certification of Tidal and Wave Energy Converters," Det Norske Veritas, DNV-OSS-312, Oct. 2008.

[14] DNV, “Position Mooring," Det Norske Veritas, DNV-OS-E301, Oct. 2008.

[15] PCCI, "Wave and Current Energy Generating Devices Criteria and Standards," PCCI, INC., Jun. 2009. 


\section{Appendix A Workshop Agenda}

\begin{tabular}{|c|c|c|c|c|c|}
\hline \multicolumn{6}{|c|}{ Day 1 - Tuesday, May 13th } \\
\hline Time & \multicolumn{4}{|c|}{ Topic (location) } & Speaker/s \\
\hline $\begin{array}{c}7: 15-8: 15 \\
\text { AM }\end{array}$ & \multicolumn{4}{|c|}{ Breakfast (Majorca Foyer) } & \\
\hline \multirow{2}{*}{$\begin{array}{c}8: 30-8: 45 \\
\text { AM }\end{array}$} & \multirow{2}{*}{\multicolumn{4}{|c|}{ Welcome and Opening Remarks (Majorca) }} & Daniel Laird, SNL \\
\hline & & & & & Ben Maurer, DOE \\
\hline $8: 45-9$ AM & \multicolumn{4}{|c|}{ WEC Developer Experience: Pelamis Wave Power (Majorca) } & Chris Retzler \\
\hline $9-9: 15$ AM & \multicolumn{4}{|c|}{ WEC Developer Experience: Columbia Power Technologies (Majorca) } & $\begin{array}{c}\text { Pukha Lenee- } \\
\text { Bluhm }\end{array}$ \\
\hline $\begin{array}{c}9: 15-9: 30 \\
\text { AM }\end{array}$ & \multicolumn{4}{|c|}{ WEC Developer Experience: Resolute Marine (Majorca) } & Darragh Clabby \\
\hline $\begin{array}{c}9: 30-9: 45 \\
\text { AM }\end{array}$ & \multicolumn{4}{|c|}{ WEC Developer Experience: NREL/WaveBob (Majorca) } & Jochem Weber \\
\hline $\begin{array}{c}9: 45-10: 15 \\
\text { AM }\end{array}$ & \multicolumn{4}{|c|}{ National Lab Perspective \& Discussion (Majorca) } & Ryan Coe \\
\hline $\begin{array}{c}10: 15-10: 30 \\
\text { AM } \\
\end{array}$ & \multicolumn{4}{|c|}{ Coffee break (Majorca Foyer) } & \\
\hline $\begin{array}{c}\text { 10:30 - } 11 \\
\text { AM }\end{array}$ & \multicolumn{4}{|c|}{ Keynote on Offshore Oil \& gas Experience (Majorca) } & $\begin{array}{l}\text { John Halkyard, } \\
\text { Halkyard Assoc. }\end{array}$ \\
\hline $\begin{array}{c}11-11: 30 \\
\text { AM }\end{array}$ & \multicolumn{4}{|c|}{ Keynote on Tank Testing (Majorca) } & $\begin{array}{l}\text { Joop Helder, } \\
\text { MARIN }\end{array}$ \\
\hline $\begin{array}{c}11: 30 \mathrm{AM}- \\
\text { 12 PM }\end{array}$ & \multicolumn{4}{|c|}{ Keynote on Numerical Modeling (Majorca) } & $\begin{array}{c}\text { Armin Troesch, } \\
\text { U. of Michigan }\end{array}$ \\
\hline $12-1 \mathrm{PM}$ & \multicolumn{4}{|c|}{ Lunch (Casablanca) } & \\
\hline $1-1: 30 \mathrm{PM}$ & \multicolumn{4}{|c|}{ Keynote on Met-Ocean (Majorca) } & $\begin{array}{l}\text { Jim Thomson, U. } \\
\text { of Washington }\end{array}$ \\
\hline $\begin{array}{c}1: 30-1: 45 \\
\text { PM }\end{array}$ & \multicolumn{4}{|c|}{ Break-Out Group Logistics and Objectives (Majorca) } & \\
\hline \multirow[b]{2}{*}{$1: 45-3$ PM } & \multicolumn{4}{|c|}{ Breakout Groups } & \\
\hline & $\begin{array}{l}\text { Physical } \\
\text { Model } \\
\text { Testing }\end{array}$ & $\begin{array}{l}\text { Numerical } \\
\text { Simulation }\end{array}$ & $\begin{array}{c}\text { The Role of Design } \\
\text { Standards \& } \\
\text { Identification of Extreme } \\
\text { Loading Conditions }\end{array}$ & $\begin{array}{c}\text { Extreme Sea } \\
\text { State } \\
\text { Characterization }\end{array}$ & \\
\hline $3-3: 15$ PM & \multicolumn{4}{|c|}{ Coffee break (Majorca Foyer) } & \\
\hline \multirow[b]{2}{*}{$3: 15-5$ PM } & \multicolumn{4}{|c|}{ Breakout Groups } & \\
\hline & $\begin{array}{l}\text { Physical } \\
\text { Model } \\
\text { Testing }\end{array}$ & $\begin{array}{l}\text { Numerical } \\
\text { Simulation }\end{array}$ & $\begin{array}{c}\text { The Role of Design } \\
\text { Standards \& } \\
\text { Identification of Extreme } \\
\text { Loading Conditions }\end{array}$ & $\begin{array}{c}\text { Extreme Sea } \\
\text { State } \\
\text { Characterization }\end{array}$ & \\
\hline $5-5: 15$ PM & \multicolumn{4}{|c|}{ Day 1 Debrief and Group Discussion (Majorca) } & NREL \& SNL \\
\hline $7-9$ PM & \multicolumn{4}{|c|}{ Group Dinner } & \\
\hline
\end{tabular}




\begin{tabular}{|c|c|c|c|c|c|}
\hline \multicolumn{6}{|c|}{ Day 2 - Wednesday, May 14th } \\
\hline Time & \multicolumn{4}{|c|}{ Topic } & Speaker \\
\hline $\begin{array}{l}7: 15-8: 15 \\
\text { AM }\end{array}$ & \multicolumn{4}{|c|}{ Breakfast (Majorca Foyer) } & \\
\hline $8: 45-9$ AM & \multicolumn{4}{|c|}{$\begin{array}{c}\text { Review Day } 2 \text { Agenda and Objectives, Review Day } 1 \text { Findings and Readjust } \\
\text { Groups as Needed (Majorca) }\end{array}$} & NREL \& SNL \\
\hline & \multicolumn{4}{|c|}{ Breakout Groups } & \\
\hline $9-10: 30 \mathrm{AM}$ & $\begin{array}{l}\text { Physical } \\
\text { Model } \\
\text { Testing }\end{array}$ & $\begin{array}{l}\text { Numerical } \\
\text { Simulation }\end{array}$ & $\begin{array}{l}\text { The Role of Design } \\
\text { Standards \& } \\
\text { Identification of Extreme } \\
\text { Loading Conditions }\end{array}$ & $\begin{array}{c}\text { Extreme Sea } \\
\text { State } \\
\text { Characterization }\end{array}$ & \\
\hline $\begin{array}{l}10: 30-10: 45 \\
\text { AM }\end{array}$ & \multicolumn{4}{|c|}{ Coffee break (Majorca Foyer) } & \\
\hline \multirow[b]{2}{*}{$\begin{array}{l}10: 45 \mathrm{AM}- \\
12 \mathrm{PM}\end{array}$} & \multicolumn{4}{|c|}{ Breakout Groups } & \\
\hline & $\begin{array}{l}\text { Physical } \\
\text { Model } \\
\text { Testing }\end{array}$ & $\begin{array}{l}\text { Numerical } \\
\text { Simulation }\end{array}$ & $\begin{array}{l}\text { The Role of Design } \\
\text { Standards \& } \\
\text { Identification of Extreme } \\
\text { Loading Conditions }\end{array}$ & $\begin{array}{c}\text { Extreme Sea } \\
\text { State } \\
\text { Characterization }\end{array}$ & \\
\hline $12-1 \mathrm{PM}$ & \multicolumn{4}{|c|}{ Lunch (Casablanca) } & \\
\hline $1-1: 30 \mathrm{PM}$ & \multicolumn{4}{|c|}{ Physical Model Testing Group Presentation and Discussion (Majorca) } & Michael Lawson \\
\hline $1: 30-2$ PM & \multicolumn{4}{|c|}{ Numerical Simulation Group Presentation and Discussion (Majorca) } & Ryan Coe \\
\hline $2-2: 30 \mathrm{PM}$ & \multicolumn{4}{|c|}{ Design Standards Group Presentation and Discussion (Majorca) } & Yi-Hsiang Yu \\
\hline $2: 30-3 \mathrm{PM}$ & \multicolumn{4}{|c|}{$\begin{array}{c}\text { Identification of Extreme Loading Conditions Group Presentation and } \\
\text { Discussion (Majorca) }\end{array}$} & Jochem Weber \\
\hline $3-3: 30 \mathrm{PM}$ & \multicolumn{4}{|c|}{ Extreme Sea State Characterization Presentation and Discussion (Majorca) } & Vince Neary \\
\hline $3: 30-5$ PM & \multicolumn{4}{|c|}{ Final Discussion and Next Steps (Majorca) } & NREL \& SNL \\
\hline
\end{tabular}




\section{Appendix B Workshop Attendees}

\begin{tabular}{|c|c|}
\hline Name & Organization \\
\hline Paul Liu & NOAA Great Lakes Environmental Research Laboratory \\
\hline Lance Manuel & University of Texas at Austin \\
\hline Eric Paterson & Virginia Tech \\
\hline Arnie Fontaine & Penn State - Applied Research Lab \\
\hline Rob Kuntz & Penn State - Applied Research Lab \\
\hline Pukha Lenee-Bluhm & Columbia Power Technologies \\
\hline Darragh Clabby & Resolute Marine \\
\hline Chris Retzler & Pelamis \\
\hline John Halkyard & Halkyard Associates \\
\hline Dominique Roddier & Principle Power \\
\hline Marco Masciola & American Bureau of Shipping \\
\hline Jarett Goldsmith & DNV GL \\
\hline Gaizka Zarraonandia & DNV GL \\
\hline Thomas Fu & Office of Naval Research \\
\hline Armin Troesch & University of Michigan \\
\hline Jim Thomson & University of Washington \\
\hline Aurélien Barbarit & Ecole Central de Nantes \\
\hline Joop Helder & MARIN \\
\hline David Newborn & Naval Surface Warfare Center - Carderock \\
\hline Miguel Quintero & Naval Surface Warfare Center - Carderock \\
\hline Ken Weems & Leidos \\
\hline Ronan Costello & National University of Ireland, Maynooth \\
\hline Solomon Yim & Oregon State University \\
\hline Mirko Previsic & Re Vision \\
\hline Bryson Robertson & University of Victoria \\
\hline Vince Neary & Sandia National Laboratories \\
\hline Ryan Coe & Sandia National Laboratories \\
\hline Daniel Laird & Sandia National Laboratories \\
\hline Diana Bull & Sandia National Laboratories \\
\hline Yi-Hsiang Yu & National Renewable Energy Laboratory \\
\hline Michael Lawson & National Renewable Energy Laboratory \\
\hline Jochem Weber & National Renewable Energy Laboratory \\
\hline
\end{tabular}




\section{Appendix C Detailed Breakout Session Findings and Notes}

This appendix presents the notes and presentation materials from the breakout sessions. The notes were lightly edited after the workshop for clarity and grammar, but care was taken not to modify the technical content. While some references are cited within this report, a more complete review of useful publications is presented in [8].

\section{C.1 Numerical Modeling}

\section{C.1.1 Participants}

The numerical modeling breakout group was composed of the following participants:

\begin{tabular}{|cc|}
\hline Participant & Organization \\
\hline Aurélien Barbarit & Ecole Central de Nantes \\
\hline Ryan Coe (moderator) & Sandia National Labs \\
\hline Rob Kuntz & Penn State ARL \\
\hline Daniel Laird & Sandia National Labs \\
\hline Pukha Lenee-Bluhm & Columbia Power Technologies \\
\hline David Newborn & Naval Surface Warfare Center, Carderock \\
\hline Eric Paterson & Virginia Tech \\
\hline Mirko Previsic & Re Vision \\
\hline Kelley Ruehl (note-taker) & Sandia National Labs \\
\hline Armin Troesch & University of Michigan \\
\hline Solomon Yim & Oregon State University \\
\hline Ken Weems & Leidos \\
\hline
\end{tabular}

\section{C.1.2 Key Findings and Recommendations}

\section{C.1.2.1 Key Findings}

- Lack of experimental data for validation: Relatively little data is publically available from tests of WECs in extreme conditions with which numerical models can be validated. Publically available datasets from well-documented experimental test campaigns would allow for better validation and thus greatly improve confidence in numerical models.

- Quantitative relative performance of numerical models: While there are a range of numerical models available for analysis of a WEC in extreme conditions (see Section Error! Reference source not found. of the Appendix of this report), their relative performance is not well characterized. To understand how these models should best be used in various scenarios, a more quantitative understanding of their relative performance (including efficiency and accuracy) is needed.

- Efficient search of survival space: Testing a survival condition with a model (numerical or experimental) is challenging partially because the most dangerous condition for a specific device cannot be known in advance. Thus part of the problem becomes searching a very large space of possible scenarios for those that pose a threat. The scenarios must be searched are comprised of irregular sea states, winds and currents, each with a distinct angle of incidence. The number of scenarios that must be evaluated prohibits the exclusive use of high-fidelity 
numerical and physical models. These more expensive and time-consuming models must be accompanied by more efficient lower-fidelity models, which can help reduce the search space to a more manageable size.

\section{C.1.2.2 Recommendations}

A. Numerical model comparison: A formal "code comparison" project could be used to provide a quantitative comparison of the various numerical models available for analysis of WECs in extreme conditions. This comparison would focus on a set of representative WEC designs (e.g., DOE Reference Models). Researchers from various institutions would then be asked to use their respective numerical codes to perform a predefined set of analyses. The results of these analyses would then be compared using a common set of metrics. If possible, physical experiments should also be conducted to provide a validation point.

B. Development/demonstration of efficient survival space search method(s) - This effort would focus on development and/or demonstration of methods to more efficiently analyze the survival of a WEC for a given deployment location. Two paths were suggested by workshop participants:

○ Lower-fidelity models can be employed to develop response surfaces on which point evaluations can employ higher-fidelity models.

- High-fidelity models can be employed to find scenarios that may cause failures of the device; searches can then be expanded in that vicinity with lower-fidelity models, using extreme sea state characterization methods to determine event frequency.

C. Numerical model improvement - Potential improvements to numerical models include:

- Viscous damping parameters can be predicted via CFD for use in lower-fidelity models.

- Wave propagation in CFD simulations can be improved, through domain decomposition or improved boundary condition formulations.

\section{C.1.3 Notes}

\section{C.1.3.1 Quantities of Interest}

The choice of a numerical model and decisions made in its implementation must take into account the nature of the specific WEC being considered. These decisions can be informed by identifying quantities of interest (QOIs). A general set QOIs for WEC survival include

- Dynamic response - The dynamic motion of the various bodies of the WEC as determined from rigid-body inertial properties and global loads. The position of the WEC relative to the free surface is needed to determine the effect of various physical phenomena (e.g., slamming and breeching). This is particularly important for oscillating water columns (due to the importance of sloshing and flooding in the moon pool).

- PCC \& joint loading - Forces and moments applied at joints and within the power conversion chain are needed for structural analyses.

- Mooring connection points - Forces induced mooring connection points on device and sea floor are needed for analysis of a device's mooring system. 
- Spatial pressure distribution - Local loads on the hull of the device are needed to inform structural analyses. When necessary, these may include peak impact pressure due to slamming.

\section{C.1.3.2 Key Physical Phenomena}

Accurate prediction of these QOIs is dependent on an adequate representation of the physical phenomena that dominate those QOIs. A list of physical phenomena key to the dynamics of WEC in survival conditions are

- Environment - The environment at a WEC deployment can be seen as the input to a numerical model.

- Waves - Waves are thought to represent the dominant forcing factor for most WEC survival scenarios. A numerical model must be capable of producing regular and irregular waves with arbitrary directionality.

- Wind - Wind loading on WECs is generally considered to be a marginal component for WEC survival. However, for WECs with large solid areas above the free surface (e.g., OWCs) wind may play a larger role.

- Current - Current, which may occur in a direction different than the primary wave spectrum, must be considered.

- Hydrodynamics - Hydrodynamic phenomena are considered to be the dominant component influencing the above listed QOIs.

- Wave modeling - Beyond specifying accurate wave conditions as the input to a model, some models (e.g., free surface Navier-Stokes) require additional consideration as to accurate propagation of waves.

○ Ideal flow - Phenomena captured by ideal flow theory must be included.

- Hydrostatics

- Froude-Krylov

- $2^{\text {nd-order drift force }}$

- Radiation

These phenomena can be characterized using frequency-domain boundary element method (BEM) codes (e.g., WAMIT). However, parameters obtained via BEM codes are only truly applicable for small amplitude motions. Models that rely on frequency-domain codes for hydrodynamic parameters can employ additional approximations, in which hydrodynamic parameters are approximated as a function of submerged geometry.

$\circ$ Viscous effects

- Slamming - Slamming during water reentry and due to steep or breaking waves should be considered, especially when spatial pressure distributions on a WEC's hull are of interest.

- Greenwater - Overtopping can influence local pressures and the dynamic response of a WEC

- Mooring - A WEC's mooring system can have a large influence on the dynamic response. Likewise, a mooring system must be designed to withstand loads created by the motions of 
the WEC. Additionally, localized loads are mooring connection points that may be of interest.

- Power conversion chain (PCC) - Numerical models used in survival analysis must be capable of including arbitrary forcing from a PCC. Many WECs are currently designed to employ survival strategies in the PCC is either "locked" or allowed to "freewheel" to reduce loading. However, research is currently underway to investigate the effectiveness of the lifeextending controls (LECs) on WECs, in which the PCC force can be modulated to reduce system loading.

- Rigid-body motion - Global loads must be coupled with rigid-body properties to predict the dynamic motion of a WEC. Models should be capable of simulating constrained motion, in which only a subset of the full six degrees-of-freedom (DOFs). Numerical models should also allow for relative motion of two coupled rigid bodies.

- Structural response - In some cases, it may be necessary to consider the structural response of a WEC. It is believed that, in most cases, structural analyses can be carried out without direct coupling with hydrodynamic models. Exceptions include highly flexible structures (e.g., Anaconda device) and slamming analyses.

\section{C.1.3.3 Available Numerical Models}

A range of numerical models are available for use in the WEC survival analysis process. In general, the cost to run a model (which must include licensing as well as computational and personnel resources) increases with model fidelity. Even with free access to today's best computational resources and highly-skilled engineers, using the highest-fidelity models for all of the simulations in a WEC survival analysis is impractical, as the models would require many years to run.

- Frequency-domain (same as time-domain Cummins') - These models assume a linear system in which reactions due to radiation and diffraction can be linearly decoupled and superimposed. These assumptions are only valid for bodies in regular waves undergoing small amplitude motion.

- Semi-empirical time-domain (Cummins' Eq. w/ nonlinear effects) - These models have their basis in the same theory used for frequency domain models, but employ Fourier transforms to operate in the time-domain. While time-domain models are based on the assumption of small amplitude motion, augmentations to account for large amplitude motions and nonlinearities are possible.

- Nonlinearities - Nonlinearities that can be added to these models include

- Hydrodynamic \& hydrostatic - These phenomena can be made a function of body position.

- PCC (control) - Arbitrary control of the PCC with force and motion saturation.

- Mooring - Mooring models can vary from simple catenary models to fully dynamic models.

- Free surface representation - Nonlinear wave formulations provide a better model of real ocean waves.

- Nonlinear potential flow - These models solve an initial boundary value problem by employing a potential flow panel method. Viscous effects must be included empirically. 
- Free surface Navier-Stokes - These are generally referred to as computational fluid dynamics (CFD) models. Free surface Navier-Stokes models represent the highest fidelity of numerical model applicable to analysis of WECs in extreme conditions. Given the proper configuration, these are capable of capturing the full range of phenomena that affect a WEC in extreme conditions.

\section{C.2 Met-ocean/Extreme Sea State Characterization}

\section{C.2.1 Participants}

The participants in the Met-Ocean breakout group are listed below:

\begin{tabular}{|cc|}
\hline Participant & Organization \\
\hline Annie Dallman (note-taker) & Sandia National Labs \\
\hline Tom Fu & Office of Naval Research \\
\hline Lance Manuel & University of Texas at Austin \\
\hline Chris Retzler & Pelamis \\
\hline Bryson Robertson & University of Victoria \\
\hline Vincent Neary (moderator) & Sandia National Labs \\
\hline Jim Thomson & University of Washington \\
\hline
\end{tabular}

\section{C.2.2 Key Findings and Recommendations}

\section{C.2.2.1 Key Findings}

- Current practices for characterizing extreme sea states exist: Current practices for offshore marine structures, [11]-[15], can be directly adapted for extreme sea state characterization.

- Return periods for WECs are different that for other structures: Although 100-yr return period events are common for marine structures, lower return periods can be used, if acceptable for survivability, when the design service life is less than 100 years [DNV 2005]. The acceptable level of risk for WECs can be quantified through a rigorous risk-based assessment that depends on the design service life, cost of device, and consequence class.

- Improved wave measurement capabilities are needed: Additional measurements and measurement capabilities are needed to more accurately predict the true distribution of extreme sea states. Buoy observations are point measurements and are therefore limited in spatial coverage, and may not represent ESS at the WEC deployment location. They typically have shorter periods of record than desired for accurate estimates of ESS (less than 20 years). Altimeters and synthetic aperture radar (SAR) measurements offer better spatial coverage, but at a low spatial and temporal resolution, which low pass filters large waves and underestimates ESS. Validated long-duration simulations may be the most practical approach to ESS characterization, but they are also known to under-bias prediction of large waves and underestimate ESS.

- Ongoing research will improve ESS characterization methods: Expected advances within the next 5 to 10 years should improve the accuracy of ESS characterization. These advances include the development of improved and more affordable monitoring instruments, improved measurement techniques (e.g., buoy arrays), adoption of higher order spectral methods (e.g. 
Janssen and Herbers), improved prediction of breaking waves, improved hindcast models and models that can simulate the effects of WEC device interaction in arrays.

\section{C.2.2.2 Recommendations}

- The WEC industry should leverage existing standards: Current practices for offshore marine structures [11]-[15] can be directly adapted by the WEC industry, but a consolidation of the existing standards in one location would make the standards easier to understand and use.

- Research is needed to do the following:

- Improve wave measurements and include better quantification of uncertainty of buoy measurements

- Determine appropriate spectra for modeling extreme wave environments

- Improve time-domain analysis of buoy data to identify individual waves and wave groups

\section{C.2.3 Notes}

The group defined four objectives that aligned with the overarching workshop objectives:

- Define the current state of the art for extreme sea state characterization ("current practice")

- Identify \& prioritize challenges and gaps (limitations of current practices)

- Recommend research pathways to most effectively advance ECM methods, including immediate recommendations for improvement, $R \& D$ needs and specific $R \& D$ activities (with time frame)

\section{C.2.3.1 Current practices}

- Use of hindcast simulations or extreme value analysis to extrapolate buoy measurements

- Extreme value theory and models used for extrapolation to events more extreme than those observed in a shorter period of record

- Use of Inverse FORM technique to define ESS; contours in the environmental space (usually significant wave height and peak period) along which contours of an extreme response with a given return period should lie [12] . Generalized Extreme Value (GEV) distribution, to estimate one variable at a time (not recommended)

- Identify one or more ESS (e.g., Hs100, T100) to describe single extreme wave or wave group (with assumed wave spectrum) as input for numerical or physical model simulation

Due to time constraints, the discussion did not include recommended practices and guidelines for ESS characterization, including guidelines and applicable design standards for offshore structures cited in Reference [11]. These are listed below:

- Guidelines for characterizing ESS are given in Ref. [11], and there are recommended practices and standards for offshore structures listed in Ref. [15] that can be directly adopted.

- Reference [11] defines three WEC deployment environments, bed-deployed-shoreline (surf zone), bed-deployed-shore (shallow water), and moored floating-offshore (deep water).

- Based on design criteria API RP 2A WSD - Fixed Offshore Structures, the recurrence interval of the ESS should be several times the planned service life of the WEC [15] 
- Based on design criteria API RP 2SK - Station keeping Systems for Floating Structures, the recurrence interval design condition for permanent moorings should be determined by a risk analysis taking into account the consequence of failure [15]

- Based on design criteria API RP 2SK - Station keeping Systems for Floating Structures, environmental loads must consider a combination of wave, current and wind conditions causing the extreme load in the design environment [15]

- Based on DNV design guidelines for wave energy converter design (Section 13.9) [11], design of the device should be based on the most severe environmental loads the structure may experience

- $\quad$ Based on design criteria API RP 2SK - Station keeping Systems for Floating Structures, the most severe directional combination of wind, wave and current forces should be specified for the permanent installation [15]

- Based on DNV design guidelines for wave energy converter design (Section 13.9) [11], The proper combinations and joint occurrences of waves and current conditions, as given in DNV-OS-C101 (Design of Offshore Steel Structures, General), should be applied [15]

- Based on DNV design guidelines for wave energy converter design (Section 15.2) [11], for WECs with a dynamic response to wave loading and or novel mooring configuration, a complete time domain simulation combined with tank testing may be necessary

- Based on EMEC guidelines on Reliability, Maintainability and Survivability of Marine Energy Conversion Systems (5.2.2.1), near-shore corrections should be considered before metocean data used to represent a site. Wave loading through the water column during storms is of particular importance [15]

- Based on DNV design guidelines for wave energy converter design (Section 15.2) [11], for WECs with a dynamic response to wave loading and or novel mooring configuration, a complete time domain simulation combined with tank testing maybe be necessary

- Based on EMEC - Wave Energy Tank Testing guidelines, (3.1), planned testing should include extreme wave loading of structure [15].

\section{C.2.3.2 Limitations}

- ESS characterization in shallow shoaling surf regions with breaking waves is especially challenging

- Buoy data are point measurements

- Extrapolated return periods of ESS are sensitive to the extreme theory or model used

- Wave buoys use different measurement technologies and have different accuracies and resolution

- Sea state measurements are typically over short periods of record less than 20 years

- Archived buoy data only have first five spectral moments (cannot reconstruct 2D phaseresolved wave group, e.g., crossing-seas)

- Long duration hindcast simulations under-bias extreme waves (See comparison of buoy and hindcast Hs plot, Fig. 2.3, M. Prevosto, Extreme and long term extrapolation, EquiMar Deliverable D2.6, January 2011) 
- Estimating the loads on offshore structures in extreme irregular waves is sensitive to the wave kinematics model used (C.T. Stansberg, O.T. Gudmestad, S.K. Haver2008. Kinematics under extreme waves. Trans. of ASME, J. of Offshore Mech. And Arctic Engrg. 130, )

- Archived hindcast simulations are not sufficiently archived (e.g. NOAA only archiving bulk parameters in WW3). Cannot reconstruct spectral shape and random wave field

- Not accounting for 'rogue waves' H>2.2Hs (Rayleigh Distribution), large wave events, breaking, Cahill PhD Dissertation.

- Rarely coupling wave, wind and current loads

- No accounting for spatial variation (arrays) of rogue waves

- No shoaling wave environments.

\section{C.2.3.3 Session overview}

WEC survival can be compromised in low and high sea states. This project narrowed the scope to focus on modeling the WEC response to an extreme sea state (ESS) because this entails special considerations and challenges in analysis, including numerical and physical modeling; not only challenges analyzing WEC response, but challenges modeling the extreme sea state as the model input.

The inverse-FORM method is applied to define an extreme sea state condition for a desired WEC deployment location. Device response in these conditions is then assessed with numerical and/or physical models. Numerical models generally consist of low to mid-fidelity codes (see "Semiempirical time-domain" models in Section C-4.3 of the Appendix of this report). Numerical modeling efforts are generally backed up with model-scale physical testing.

Extreme sea state characterization challenges: Buoy observations are point measurements, are limited in spatial coverage, and may not be representative of ESS at the WEC deployment location. They typically have shorter periods of record (less than twenty years) than desired for accurate estimates of ESS. Altimeters and synthetic aperture radar (SAR) measurements offer better spatial coverage, but at a low spatial and temporal resolution, which low pass filters large waves and underestimates ESS. Validated long-duration hindcast simulations may be the most practical approach to ESS characterization, but they are also known to under-bias prediction of large waves and underestimate ESS.

For ESS characterization, current practices for offshore marine structures [11]-[15] can be directly adapted. Nevertheless, the ESS breakout group outlined the limitations of current practice methods, recommendations for improving ESS characterization, expectations for advancing ESS measurement and modeling techniques and recommended research pathways.

During the breakout group discussion, the following key findings and recommendations were discussed:

- Quantify uncertainty with buoy measurements (e.g., JCOMM)

- Use full (well resolved) spectral information

- reconstruct complete wave field (nonlinear preferred, but linear ok); At least 100 crests 
- Or partition to different unique wave trains (separate swells and wind waves); Way to improve inverse FORM method

- If buoy data can be obtained, use time-domain analysis of buoy data to identify individual waves and groups

- Use wave time series and zero crossing analysis to identify large waves (e.g., Tucker and Pitt - Cahill Thesis)

- Include wave steepness as additional parameter

\section{C.2.3.4 Expected R\&D Advances (time frame)}

- 2D phase resolved descriptions (sequence and timing of waves in wave groups), measurement and modeling, 10-year time frame

- $\quad$ Need to reduce cost of instruments, 5-years

- New measurement techniques (Thomson): Doppler radar, scanning LiDAR, buoy arrays, 5-years

- Deployment \& adoption of newer measurement devices, 5-years

- Adoption of higher order spectral methods (e.g., Janssen and Herbers), 5-years

- Predictive tools for breaking (measurement and modeling), 5-years

- Improved hindcast models (better wind inputs) to better resolve extreme waves, 5-years

- Array effects on ESS and environmental loading, 5-years

- Improvements in characterizing ESS in near-shore environments, 5-years

\section{C.2.3.5 Research Paths}

- Complete review of current practice in seakeeping, offshore oil \& gas, offshore wind

- Demonstration project (DOE Reference Model WEC)

- Improved wave measurement techniques

- Rough/approximate description of 2D phase resolved wave field

- Use partitioned spectra to perform Inverse FORM method for site/device pair (DOE reference model, Humboldt Bay)

- Coupling of wave, current and wind loads

- Evaluate value of recommendations

- 5-10 year effort

- Working Group, international Technical Specification on WEC survivability analysis (e.g., IEC, IEA, ISSC, ITTC)

- Identify other international researchers working on extreme sea state analysis 


\section{C.3 Physical Modeling}

\section{C.3.1 Participants}

The participants in the Physical Modeling breakout group are listed below:

\begin{tabular}{|cc|}
\hline Participant & Organization \\
\hline Michael Lawson (moderator) & National Renewable Energy Laboratory \\
\hline Diana Bull (co-moderator) & Sandia National Laboratories \\
\hline Chris Rensler & Pelamis Wave Power \\
\hline Dominique Roddier & Principle Power \\
\hline Joop Helder & MARIN \\
\hline Miguel Quintero & Naval Surface Warfare Center - Carderock \\
\hline Ronan Costello & National University of Ireland, Maynooth \\
\hline
\end{tabular}

\section{C.3.2 Key Findings and Recommendations}

\section{C.3.2.1 Key Findings}

- Experimental methods being used are from offshore oil \& gas and shipping industries: Developers are using experimental methods developed by the shipping and offshore oil \& gas industries.

- Extreme loads are not necessarily the result of the largest wave: Extreme loading events are typically a series of waves from a specific wave train as opposed to simply the largest wave. Accordingly, focused waves in a wave tank test may not be the most appropriate way to test device performance in extreme conditions.

- WECs will not be designed to the same level as ships or offshore platforms: The industry needs a way to determine what condition to design to (see the risk-based design in the Standards breakout session). In other words, depending on cost and consequence class, should extreme conditions be defined as a 20-year storm, 50-year storm, or 100-year storm. In addition, it is important to develop appropriate safety factors to apply during the extreme loads design process and these factors may be different than those used by the offshore oil \& gas and shipping industries.

- Testing devices with deformable bodies is difficult: It is difficult to test WECs that rely on deformable body dynamics because of material scaling properties. It is unclear whether there are enough developers perusing this type of technology to justify investment in developing experimental modeling techniques.

\section{C.3.2.2 Recommendations}

- Develop improved methods of modeling power take off systems at small scale: Powertake-off systems are difficult to test accurately at small scale and R\&D and testing methods improvement are needed and should be developed

- Consolidate existing standards and design guidelines: There are several design and testing guidelines currently under development (e.g. International Electrotechnical Commission, International Towing Tank Conference, ABS, DNV-GL). However it is not always clear what 
standards should be followed and the existing standards should be consolidated in one location (perhaps OpenEI) for clarity.

- Insure that all measurements are of appropriate time resolution and are time synced: During testing, all experimental measurements should be time synced.

- Calibrate wave tanks before testing: Calibration of wave tanks is critical and it should be confirmed the tank is accurately calibrated before testing begins.

- Perform numerical simulations at the same time as experimental tests: Numerical simulations should always be performed simultaneously with wave tank tests so that any problems with the experiments can be identified before testing is complete.

- Insure PTO systems are accurately modeled in scale experimental tests: PTO system scaling is very difficult. Scale PTO systems should be constructed very carefully to insure proper performance, or electric motors should be used in place of scale PTO systems to insure the forces acting on the device are correct.

\section{C.3.3 Notes}

\section{C.3.3.1 Current state-of-the-art}

- Extreme wave conditions are difficult to define. Tests are often performed with 100-year wave or wave environment that developers identify as particularly harmful to their device

- Water current and wind is not considered at this point. For some (but likely not all) devices, these effects may be important.

- Instrumentation of critical systems and/or failure points. Detailed measurements (e.g. pressure distributions) are not typically made due to associated cost and complexity.

- Experimental methods developed for oil \& gas and shipping industry are heavily leveraged. Little methods development has been performed by the wave industry.

- What are the important experimental design considerations?

- Important that the mass properties (mass and moments of inertia) are accurately represented in the experimental tests

- Testing different survival scenarios may require different scale models and/or tests

- Instrumentation can be problematic for small device scales, as the required instrumentation may effect inertial properties

- Need to think about what the purpose of experimental tests are before the tests are performed. Need to ask, what do we want to measure/validate/verify. Then a test plan should be developed. This type of systematic approach is not always the standard in the WEC industry.

- Real-time processing of data is important.

- Real-time data analysis should be performed during the experiments

- Data processing ensures the results are useful

- Simulations should also be run real time to find numerical model and experimental test problems so they can be addressed while in the tank - this is not possible after testing has been completed.

- Video is important

- Some redundant measurements make sense given the expense of tank testing 


\section{C.3.3.2 Gaps}

- Small scale is desirable for Froude scaling/tank limitations, but makes PTO modeling difficult and causes problems with Reynolds number not scaling properly.

- Model PTO systems are not typically repeatable $\rightarrow$ needs more attention and electronic PTO systems show promise.

- Effective ways to test different failure modes in tank tests - consider when designing tank test program test conditions where there are PTO failures / test when PTO is operational, but grid connection is lost, i.e. fault conditions / what happens if device does not go into "survival mode" during survival condition

- How to identify failure modes and conditions that cause them (i.e. limit states for the system) - well defined for oil \& gas, but not yet for WECs

- Test fault conditions

- Developers have traditionally used focused waves to test extreme conditions performance of device. This is not best practice and a response base analysis (i.e. determination of what wave trains cause the largest loads) should be used

- Calibration of wave tanks is critical and not all tanks are well calibrated - especially the low budget tanks that are typically used by smaller developers (which is a larger percentage of the wave energy industry). Wave tank characterization includes the characterization of reflections, basin coverage, energy density, etc.

- Running numerical models at the same time that experimental measurements are performed. Numerical simulations can help identify for existing tanks

- Testers should always run and check tank with no model present - seems to be standard practice - developers and testers need to account for calibration time when they are developing test plans

- There are other necessary testing conditions - e.g. tow out, dry lift, installation, O\&M, mooring installation, arrays, accidents, boat strike. These conditions are not typically considered as seriously as extreme loads that occur after the installation is completed, even though they are just as important.

- Testing deformable devices (AWS, anaconda) is a challenge - relevant when deformations are large enough to radiate waves - also important when deformation is critical to PTO operation due to scaling issues and when the performance of deformable components need to be tested at scale.

- Syncing and data logging - need a "data unifier" for inexpensive tanks - important if you want to look at results real-time - can save post-processing time and make results more useful after testing is compete.

○ Possibly attach data logging requirements to DOE funding for tests?

- Approval of test plans?

○ More automation in testing could help - sensors must be compatible with measurement systems

- follow ITTC procedures

- Difficult to measure pressure distributions for numerical validation - point measurements are standard, spatially resolved measurements are a more "research-level" topic and are typically very expensive 
- Material scaling is typically not considered at model scale $\rightarrow$ loads are passes to FEA/structural software for more detailed analysis

- Small scale tanks $(\sim 100 \mathrm{~K})$ - there is a company that makes one of these - the cost of tank testing is mostly the experts required to run the tests/setup instrumentation

\section{C.3.3.3 What are the next steps?}

- Develop a U.S. (likely DOE) program similar to MARINET (http://www.fp7-MARINET.eu/). Critical components of this program would be:

- Access to wave tanks

○ Characterization of wave tanks prior to testing

- Reflections

- Directional waves

- Basin coverage - i.e. where are the "dead spots" and what is the energy distribution

- Technical/engineering support for test planning, model construction mooring system, PTO system development, and post-processing - move responsibility for model construction away from developers/testers towards tanks - important that testing center is involved with the design and fabrication of the test model - models should be built with the test facility in mind - approval of test plan/model design

- Require publication in peer-reviewed conference/journals so that the tank testing is not just a "box checking" exercise

- Explore possibilities of requiring numerical modeling prior to wave tank testing

- relevant to do before going into the tank to check for design problems

- should be performed by a third party to verify design specifications

- can help develop experimental test plan

- leverage DOE/National Lab computing facilities

- Example test programs to represent some set of likely deployment locations - these guidelines would include extreme seas

- Requirements/test plan should reflect the level of development/cost of the device and test

○ Give priority to developers who 'need' the test

- Testing guidelines - consolidate existing guidelines - e.g. ITTC

○ Require that tests follow guidelines or provide rational/justification for not following guidelines

- Example test programs (super program and everyone tests a subset)

- Recommended test conditions to cause extreme loading - require to be simulated numerically before it is tested experimentally

- Require several different extreme conditions to be considered - e.g. short steep waves, long waves, etc

- Having a reviewed and approved test plan is perhaps better than requiring developers to exactly follow ITTC standards - by DOE determined group (e.g. DVNGL/National Labs/testing facilities) 
- Development of generic PTO systems (e.g. linear rotary) that enable the testing of scale devices - this is challenging because there is very little convergence within the industry

o Important because friction is a big problem at model scale - very relevant to a U.S. MARINET program

- Important to do bench-top testing of PTO / dynamic calibrations to determine response - is it linear, non-linear, etc. - complete before test

- PLC development that can be used with different motors

- Develop methods to experimentally recreate wave trains that are appropriate to replicate realistic extreme sea states (met-ocean breakout group will look into this in more detail)

- Open-source data processing tools for making sense of raw data

○ Some useful tools exist - DIWASP, WAFO

- Ability to easily model non-linear waves in wave tank tests

\section{C.3.3.4 What tanks can be used for ECM testing?}

- University of Maine (coming soon)

- OSU

- Carderock

- MARIN

- ECN

- And many others depending on acceptable scale

\section{C.4 Design Standards and Extreme Loading Conditions}

\section{C.4.1 Participants}

The participants in the Design Standards and Extreme Loading Conditions breakout group are listed below:

\begin{tabular}{|cc|}
\hline Participant & Organization \\
\hline Jochem Weber (moderator) & National Renewable Energy Laboratory \\
\hline Jarett Goldsmith & DNV-GL \\
\hline Yi-Hsiang Yu & National Renewable Energy Laboratory \\
\hline Diana Bull (note-taker) & Sandia National Laboratories \\
\hline Gaizka Zarraonandia & DNV-GL \\
\hline Arnie Fontaine & Penn State ARL \\
\hline Marco Masciola & ABS \\
\hline
\end{tabular}

\section{C.4.2 Key Findings and Recommendations}

\section{C.4.2.1 Key findings}

- No standards exist: Although there are guidelines (DNV OSS 312, Equimar, and Carbon Trust), applicable standards, and experience from offshore wind, naval architecture, and oil \& gas, there are no dedicated standards for WEC design, particularly for extreme conditions. Wave energy developers often use offshore oil \& gas standards as a starting point. 
- Failure modes effects analysis (FMEA): Not every WEC developer had conducted a detailed FMEA analysis and identified extreme/ultimate limit states for their design during the development process.

- Lack of data/experience. The WEC industry is at the nascent stage. Only a limited number of WEC devices have been deployed and tested in the water. The WEC community lacks data, including WEC system information, detailed environmental conditions, structural loads and associated conditions, failures and root causes, overall experience and safety factors used.

- Uncertainty in determining extreme loading conditions: WEC developers often face the question of how to estimate the extreme loading conditions, which can be different for different WEC devices and different device components. It is challenging to identify the extreme conditions, which can be extreme sea states or a sequence of operational waves with relatively large amplitudes. In addition, numerical/experimental methods may still result in high uncertainty, including scaling issues, appropriate representation of all coupled systems, and the limitation of methods to represent accidental/survival/temporary conditions.

\section{C.4.2.2 Recommendations}

- Develop design standards: Currently, DNV and other certifying bodies are working to develop guidelines and the development of standards, and the IEC is working on the draft of a design requirements document. A risk-based approach has been suggested and the standards development will also rely on other industry experience where applicable (e.g. particular systems, subsystems for the WEC devices).

- Use a risk-based approach for design standards: One key difference between WECs and other offshore structures is that the risks (loss of investment, loss of life, environmental impact) associated with the failure of a WEC are much less than for most offshore structures (with the notable exception of offshore wind turbines) and ships. A risk-based design approach is suggested, which evaluates the design, impact, and failure probability of the device components relative to the cost. The steps include defining modes of operation, technology assessment, and FMEA analysis and specification of design load cases. For the design standard development, the interim goal is to lead to a "Statement of Feasibility" and the final goal is to use for certification.

- Share WEC industry data and experience. To gather more data from all the WEC testing projects, it is essential to ensure all prototypes are instrumented to capture detailed environmental condition and load data and give the WEC developer access to resources in modeling and testing (e.g. access to expertise/computing resources/basins). The MARINET project is a successful example, and Joint Industry Projects (JIPs) are also an option. Test centers and the leasing agency (Bureau of Ocean Energy Management) can play an essential role in pushing for data and experience sharing in the WEC community.

- Improve met-ocean/extreme sea state, numerical and physical modeling: See Appendix C.2

\section{C.4.3 Notes}

\section{C.4.3.1 Design Standards}

- What are the existing standards and are they relevant to the WEC industry? 
- No standards exist, although IEC TC114 is in the process of developing a set of wave and tidal device standards. There are guidelines: DNV OSS 312, Equimar, Carbon Trust, applicable standards and experience from offshore wind and oil \& gas, (shipping)

- Risk-based approach is applied

- Defining modes of operation

- Technology assessment and failure mode identification

- Specification of design load cases

- Interim goal: To lead to "Statement of Feasibility"

- Final goal: Certification of compliance

- Are there gaps in the existing standards?

- Yes, lots. The whole approach is different to a traditional standards approach.

- Scope of design basis

- Deployment met-ocean conditions

- Modes of operation

- Configuration of all systems

- System specifications

- Structural

- Mechanical

- Electrical

- Can the developers be provided with advice when best to start the process?

- Roughly when the developer plans for sea going tests and will undertake relevant and same design tank testing campaign for this sea going campaign

- Specifically when they can provide all the information required for the establishment of the design basis

- Certification is not compulsory

- To ensure best practices \& reduce risk.

- Is there need for additional standards development?

- Yes, but the diversity of WECs requires a flexible approach

- Many load cases need to be considered: Thousands

- Baseline safety factors need to be derived for specific cases and risks

- Gap to be filled: Collection of data to help determine safety factors.

- How does the topic relate to other breakout groups?

- What are the critical design load conditions (DLCs), including identification of extreme loads?

- Key survival conditions may not be associated with extreme wave events

- Well-defined met-ocean characterization needed

- Understanding of uncertainty from met-ocean characterization, physical modeling, and numerical modeling methods applied

- Physical understanding of key risks and consequences for each WEC device (FMEA)

- Once design basis and DLCs are known (i.e. from FMEA), appropriate numerical/physical modeling techniques need to be applied

- The certification process can help developer progress through design, including reliability and survivability considerations. 
- How can standards be written for an industry that has not converged on a winning design archetype?

- $\quad$ Risk-based approach (e.g. DNV OSS 312) can be used.

- Rely on other industry experience where applicable (e.g. particular systems, subsystems)

- Is the work being performed by IEC TC 114 on target?

- The 62600-2 Design Requirements document is still being drafted (unknown if 'on target')

- IEC TC 114 is discussing this risk-based approach as the appropriate way to go forward.

- How should the standard development community work to best help the WEC industry and vice versa?

- Lack of data is a problem. WEC industry needs to share their experience.

- WEC industry can help by providing data.

- WEC system information, detailed environmental conditions, structural loads and associated conditions, failures and root causes, overall experience and safety factors used

\section{C.4.3.2 Identification of Extreme Loading Conditions}

- How is the WEC industry currently identifying conditions where extreme device loading occurs?

- Each developer has their own processes

- Often using offshore oil \& gas standards (as starting point, or as sole source of environmental condition recommendations)

- Identification of conditions through experimental (often) and numerical modeling campaigns

- Careful application of techniques (see other groups), and awareness of limitations is critical

- What gaps in existing methods are holding the industry back?

- Not everyone is identifying extreme/ultimate limit states through FMEA (risk assessments) - Living document.

- $\quad$ Numerical/experimental methods may still result in high uncertainty

- Scaling issues

- Appropriate representation of all coupled systems

- Representation of sea states in physical modeling

- Limitation of test basins/measurement instrumentation

- Limitation of numerical methods to represent accidental/survival/temporary conditions

- Validation of numerical models

- $\quad$ Not everyone has well-defined test plans or follow them

- What research could help address these gaps?

- Training in risk-based design approaches

- E.g. example of detailed FMECAs (applied to reference model or publically known design) 
- Ensure all prototypes are instrumented to capture detailed environmental condition and load data

- Including full-scale deployments

- Role of test centers and leasing agency (BOEM)

- Giving access to resources in modeling and testing (e.g. access to expertise/computing resources/basins) - MARINET model

- But need to consider sharing of data

- Joint Industry Projects (JIPs) and sharing of data

- Under what conditions do WECs experience extreme loads?

- Depends on each individual WEC

- Potential for some similarities/trends (particularly among similar WEC types)

- E.g. connection points, end stops, resonance, system memory or time accumulated effects, breaking wave impacts, high accelerations, steep high frequency waves, tow out, installation, directionality issues, superposition of different environmental conditions, slap/slam, green water.

- Potential to learn from other industries (e.g. moorings loads)

- What type of numerical and experimental methods can be used to model devices under the different type of extreme loading conditions?

- Experimental: See other Experimental group

- Numerical: See other Numerical group 


\section{Appendix D Post-Workshop Questionnaire Responses}

Following the workshop, attendees were encouraged to fill out the online questionnaire presented in the Figure D-1. Table D-1 presents the attendees responses to the questions. Note that the responses are anonymized.

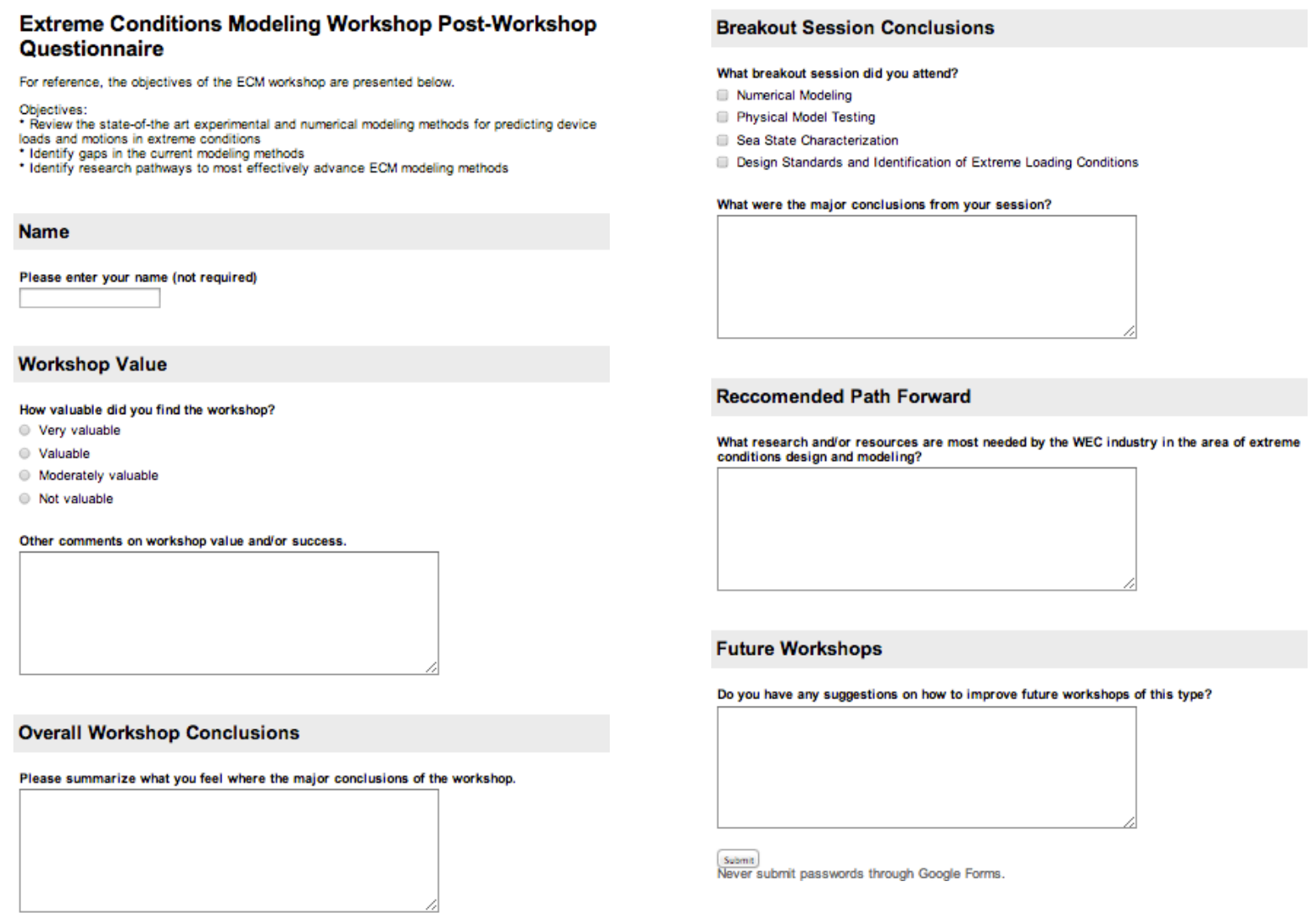

Figure D-1. Post-workshop questionnaire that attendees were asked to complete. 
Table D-1. Response to the post-workshop questionnaire.

\begin{tabular}{|c|c|}
\hline & $\begin{array}{l}\text { Please summarize what you feel where the major conclusions of } \\
\text { the workshop. }\end{array}$ \\
\hline Response 1 & $\begin{array}{l}\text { There is still a lot too be done, and technology developers still need a } \\
\text { lot of help! }\end{array}$ \\
\hline Response 2 & $\begin{array}{l}\text { - Extreme WEC conditions not confined to extreme wave conditions } \\
\text { - Low fidelity numerical models (e.g. linear frequency and semi non- } \\
\text { linear time domain models) often incapable of representing extreme } \\
\text { conditions } \\
\text { - High fidelity numerical models (CFD) are often as costly as tank } \\
\text { testing. Furthermore, it is likely that they will need to be verified against } \\
\text { model measured in tank. } \\
\text { - Numerical modelling offers more complete simulations as it is not } \\
\text { subject to instrumentation limitations (pressure distributions, PTO } \\
\text { simulation). } \\
\text { Numerical and physical models should be developed in a } \\
\text { complementary fashion. } \\
\text { Identification of extreme wave conditions from MetOcean data by } \\
\text { extrapolation of probability distribution (Weibull) may underestimate } \\
\text { extreme conditions. }\end{array}$ \\
\hline Response 3 & $\begin{array}{l}\text { * standardization of design for survival of WECs is difficult as there is } \\
\text { such a wide variety of devices } \\
\text { * modeling tools, appropriate for extreme condtions / response, that } \\
\text { balance accuracy and speed/cost, are not necessarily available. a } \\
\text { hybrid approach where mid and high fidelity tools are used may be } \\
\text { necessary } \\
\text { * the data/tools necessary for accurate, site specific extreme conditions } \\
\text { estimations are not necessarily available }\end{array}$ \\
\hline Response 4 & $\begin{array}{l}\text { - There is considerable amount of work to be done in this field. } \\
\text { - Experience and knowledge can be imported from other ocean } \\
\text { engineering fields yet must be tailored for the wave energy industry. } \\
\text { - Additional measurements and measurement capabilities to determine } \\
\text { the true distribution of extreme wave events are required. } \\
\text { - There are numerical tools at the disposal of researchers, yet a detailed } \\
\text { description and independent analysis of each is vital to efficient use to } \\
\text { time and resources. }\end{array}$ \\
\hline
\end{tabular}




\begin{tabular}{|c|c|}
\hline Response 5 & $\begin{array}{l}\text { - Extreme behaviour/conditions are technology dependent. Need to be } \\
\text { identified by developer first. } \\
\text { - End stops are critical regarding survivability of WECs. Should be } \\
\text { avoided whenever possible. End stops may be showstoppers actually. } \\
\text { - US MARINET like project sounds like a great idea, however issues } \\
\text { identified with the EU MARINET needs to be adressed. } \\
\text { - CFD is not a pratical option for WEC developers. CFD needs experts } \\
\text { for correct use. Developers do not have the required resources. }\end{array}$ \\
\hline & $\begin{array}{l}\text { What breakout session did you attend and what were the major } \\
\text { conclusions from your session? }\end{array}$ \\
\hline Response 1 & $\begin{array}{l}\text { Physical Model Testing: } \\
\text { Need to create a system in the US similar to the mariner project in } \\
\text { europe to help small companies develop their ideas technically better } \\
\text { before going to the prototype stage. Additionally to lab time, giving } \\
\text { those companies support time from expert engineering companies on } \\
\text { modeling would deb a good thing. }\end{array}$ \\
\hline Response 2 & $\begin{array}{l}\text { Physical Model Testing: } \\
\text {-A Marinet style framework in the US to assist developers in the } \\
\text { successful implementation of tank test campaigns. } \\
\text { - While standards and recommended practises exist for tank testing } \\
\text { WECs, they have not been adopted. This should be encouraged. } \\
\text { PTO simulation is very difficult to implement in physical model tests. A } \\
\text { generic PTO simulator would be ideal. However, given the wide range } \\
\text { of WEC configurations, A truly generic solution may not be feasible. }\end{array}$ \\
\hline Response 3 & $\begin{array}{l}\text { Numerical Modeling: } \\
{ }^{*} \text { modeling tools, appropriate for extreme condtions / response, that } \\
\text { balance accuracy and speed/cost, are not necessarily available. a } \\
\text { hybrid approach where mid and high fidelity tools are used may be } \\
\text { necessary } \\
{ }^{*} \text { CFD tools may be used judiciously to support a robust modeling } \\
\text { program }\end{array}$ \\
\hline Response 4 & Sea State Characterization: Reported in the break-out group notes. \\
\hline Response 5 & $\begin{array}{l}\text { Numerical Modeling, Physical Model Testing: } \\
\text { - CFD is not a pratical option for WEC developers. CFD needs experts } \\
\text { for correct use. Developers do not have the required resources (people } \\
\text { and computational resources) } \\
\text { - US MARINET like project sounds like a great idea, however issues } \\
\text { identified with the EU MARINET needs to be adressed. }\end{array}$ \\
\hline Response 6 & Sea State Characterization \\
\hline
\end{tabular}




\begin{tabular}{|c|c|}
\hline & $\begin{array}{l}\text { What research and/or resources are most needed by the WEC } \\
\text { industry in the area of extreme conditions design and modeling? }\end{array}$ \\
\hline Response 1 & Funding, and dissemination of know how. \\
\hline Response 2 & $\begin{array}{l}\text { 1. Developer access to tank facilities } \\
\text { 2. Assistance in the development of physical models (instrumentation, } \\
\text { PTO simulation) } \\
\text { 3. Reduction in cost of high fidelity numerical modelling tools ... or } \\
\text { improvement in fidelity of low cost numerical modelling tools! }\end{array}$ \\
\hline Response 3 & $\begin{array}{l}{ }^{*} \text { evaluation and bench marking of available numerical modeling } \\
\text { packages for a variety of WEC types in extreme conditions / response } \\
{ }^{*} \text { methodology for identifying conditions (and instances) resulting in } \\
\text { potential failure }\end{array}$ \\
\hline Response 4 & $\begin{array}{l}\text { - Better ability to determine the true distribution of extreme wave events } \\
\text { for each geographic locations. } \\
\text { - A quantitative understanding of the risks WEC developers are willing } \\
\text { to undertake in order to minimize the costs of designing for } \\
100 / 500 / 1000 \text { year events. }\end{array}$ \\
\hline Response 5 & $\begin{array}{l}\text { - Access to experimental facilities and numerical resources. } \\
\text { - Access to expertise to make good use of these resources. }\end{array}$ \\
\hline & $\begin{array}{l}\text { Do you have any suggestions on how to improve future workshops } \\
\text { of this type? }\end{array}$ \\
\hline Response 1 & $\begin{array}{l}\text { Well let see if the workshop has any impact on DOE, if it does, we ought } \\
\text { to have more. }\end{array}$ \\
\hline Response 2 & $\begin{array}{l}\text { This workshop (like many others in this field) was dominated by } \\
\text { representatives from research institutions, with only three } \\
\text { representatives from WEC developers (Pelamis, Columbia Power, and } \\
\text { RME). } \\
\text { In addressing the conclusions drawn by this workshop (particularly the } \\
\text { development of a Marinet style project) success will require a more } \\
\text { balanced approach between those on the supply side (research } \\
\text { institutions, tank facilities) and those on the demand side (developers). } \\
\text { Having said this, it seems that the three developers in attendance were } \\
\text { given precedence as they were each invited to give presentations at the } \\
\text { start of the workshop. Perhaps the poor representation of developers } \\
\text { was due to unwillingness on their part to engage? }\end{array}$ \\
\hline Response 3 & $\begin{array}{l}\text { a little more time, and a little more focus (ie reining in of wandering } \\
\text { conversations) }\end{array}$ \\
\hline
\end{tabular}




\begin{tabular}{|l|l|} 
Response 4 & $\begin{array}{l}\text { - Excellent conference in general. } \\
\text { - An additional workshop to disseminate the findings from each group. } \\
\text { There was considerable need to understand the events taking place in } \\
\text { other groups in order to determine the best path forward to your group. } \\
\text { All "break-out" groups are connected and information flow is important. }\end{array}$ \\
\hline Response 5 5 It was all very good. Maybe it would have been better to engage more \\
& $\begin{array}{l}\text { WEC developers, or to survey what they believe are their issues prior to } \\
\text { the workshop. }\end{array}$ \\
\hline & \\
\hline & How valuable did you find the workshop? \\
\hline Response 1 & Very valuable \\
\hline Response 2 & Valuable \\
\hline Response 3 & Valuable \\
\hline Response 4 & Very valuable \\
\hline Response 5 & Very valuable \\
\hline Response 6 & Valuable \\
\hline
\end{tabular}

\begin{tabular}{|l|l|}
\hline Response 1 & $\begin{array}{l}\text { Other comments on workshop value and/or success. } \\
\text { discipline together, only something good can come out of that.. } \\
\text { I feel that some of the recommendations to DOE that cam out of the } \\
\text { conclusions are very good and hope they can be implemented }\end{array}$ \\
\hline Response 2 & $\begin{array}{l}\text { The format of this workshop made for very productive discussion as } \\
\text { there was a good mix of presentation and discussion. Workshops } \\
\text { dominated by presentations often risk isolating the majority of the } \\
\text { participants, while those dominated by discussion may descend into } \\
\text { long unstructured rambling! This workshop's mix of these two elements } \\
\text { made for a very efficient format. }\end{array}$ \\
\hline Response 3 3 & $\begin{array}{l}\text { it was a huge topic, perhaps one additional day would have been } \\
\text { beneficial }\end{array}$ \\
\hline
\end{tabular}

